\title{
Concejo abierto, regimiento y corregimiento en Guadalajara (1346-1546)
}

\author{
José Miguel López VilLai.ba
}

Durante la Alta Edad Media Hispánica se consolidó una forma de gobierno municipal que conocemos como concejo abierto. Dicho concejo, del que teóricamente formaban parte todos los vecinos de cada lugar -aunque se ha demostrado que éste era un supuesto erróneo-, evolucionó con lentitud hacia formas más oligárquicas hasta dar paso a un gobierno reducido ', conocido como regimiento o cabildo de regidores, que tomó para sí todas las competencias municipales, las cuales conllevaban un dominio absoluto de la vida local, incluida desde luego la actividad económica. Las oligarquias urbanas procuraron desde el primer momento acaparar los cargos de regidor nombrados por el rey.

En algunas poblaciones la fecha de instauración del regimiento es temprana. Asi, 1342 para Zamora, 1345 para Burgos y 1346 para Madrid ? Otras ciudades, sin embargo, no adoptaron el nuevo sistema de gobierno hasta mucho después. La villa de Guadalajara no lo tendria hasta comienzos del siglo xv.

José Antonio Escudero advierte que cel concejo abierto se tornó inviable en la práctica, debido fundamentalmente a dos causas. De un lado el creciente número de vecinos que dificultaba la posibilidad de celebrar las asambleas. De otro la complicación de la vida municipal, cuyos diversos asuntos dificilmente podian ser discutidos y resueltos por esa muchedumbre indiscriminada". Curso de Historia del Derecho. Madrid 1985, pág. 586.

2 Para el concejo de Burgos: Bonachia Hernando, J. A., El Concejo de Burgos en la Baja Edad Media. Valladolid 1978, y Gonzalez Diez, El Concejo Burgales (884-1369). Marco histórico-constitucional. Burgos 1985. Para el de Zamora, LADero Quesada, Manuel Fernando, La ciudad de Zamora en la época de los Reyes Católicos. Economia y Gobierno. Zamora 1991. Para Madrid, GiBert, Rafael, El Concejo de Madrid. Su organización en los siglos xil al xv. Madrid 1949. 
Se atribuye la extension del regimiento a las reformas de Alfonso XI. Mas no puede decirse que dicho rey fuera el único artifice de esta intromisión regia en la politica municipal, sino que culminó una tendencia anterior $^{3}$. Y por otra parte, una serie de factores, bien establecidos por Cerdá Ruiz-Funes ${ }^{4}$, minaron el concejo abierto desde el siglo xIII, de modo que el nombramiento de regidores en las ciudades castellanas a partir del decenio de 1340 , respondió tanto a una política de fiscalización real como a unos nuevos problemas que el régimen anterior no podia resolver.

El número de regidores no fue el mismo en todas las ciudades: Unas veces fueron ocho, como en Guadalajara; otras diez, doce, o veinticuatro, como los emblemáticos regidores de Sevilla o los de Cuenca ${ }^{5}$. En algunas ciudades este número permaneció invariable durante largo tiempo, como en Zamora ${ }^{6}$ o Guadalajara.

El propósito de nuestro trabajo, es establecer las principales etapas de la historia del gobierno local de Guadalajara, antes y después del regimiento. Las fuentes principales son las ordenanzas - de 1346, 1405, 1417 y 1546- y los libros de actas de sesiones que conserva el Archivo Municipal de Guadalajara.

\section{ANTES DEL REGIMIENTO: LOS HOMBRES BUENOS}

La oligarquización del gobierno local fue un proceso lento, que a veces duró varias decenas de años. En principio, el Concejo abierto fue que-

${ }^{3}$ Pérez Prendes, José Manuel, cEl ordenamiento de las Cortes de Alcalá de 1348, introdujo una serie de transformaciones en el Derecho Castellano y se le puede considerar simbólicamente como el hito que marca el final del periodo altomedieval en el aspecto legislativo". Curso de Historia del Derecho Español. Vol. I., pág. 711. Madrid, Universidad Complutense, 1984.

${ }^{4}$ Cerdó Ruiz-Funes, Joaquín, en su articulo: “Hombres buenos, jurados y regidores en los municipios castellanos de la Baja Edad Media", en Actas del / Symposiun de Historia de la Administración. Madrid 1970, págs. 180-181, puntualiza que dichos factores serian: los socioeconómicos, la disensiones ciudadanas, el demográfico, situación de las instituciones locales de tipo tradicional y los precedentes del concejo reducido entre otros.

' Cabañas Gonzalez, Maria Dolores, La caballería Popular en Cuenca durante la Baja Edad Media. Madrid 1980. La profesora Cabañas González, aporta datos para la ciudad de Cuenca según los cuales en las Ordenanzas que Fernando de Antequera otorgó en 1411 a dicha ciudad y que posteriormente fueron confirmadas por Juan II, habia 24 regidores, que despues se redujeron a nueve y finalmente aumentaron a 15 en el año 1455 .

${ }^{6}$ Ladero Quesada, M. F., afirma que en Zamora el número de dieciséis regidores que aparece en 1342 se mantiene y permanece constante a lo largo de la Baja Edad Media y el siglo xvı. Op. cit., pág. 150. 
dando en manos del grupo de "hombres buenos" ', con reputación de justos, honrados y leales ${ }^{8}$. Esos hombres buenos son el antecedente directo de los regidores ${ }^{9}$.

Así, aunque en la villa de Guadalajara no encontramos noticias del oficio de regidor hasta 1405, las ordenanzas de 1346, de las que nos ocupamos a continuación, confirman la existencia de un gobierno de doce hombres buenos.

Esos hombres buenos, junto con cierto alcalde Benito Pérez, redactaron las citadas ordenanzas por mandato de la reina, a quien los pecheros de la villa, que no debían estar muy contentos con el gobierno municipal, habian elevado previamente su petición. La reina delegó su poder en Tel Fernández de Toledo y Garci Alonso Triguero de Toro, alcalde mayor y alcalde de las alzadas de la casa real, respectivamente. La casa del judío Abraham Alfandaji, hospedaje del alcalde mayor Tel Fernández, sirvió de centro de reunión el dia 1 de diciembre de 1346. Nueve de los doce hombres buenos acudieron ese día. $Y$ acudieron también los "quatro", representantes de los pecheros, para explicar a los representantes de la reina los agravios que sufría el común.

Veintidos días más tarde volvieron a reunirse, esta vez en casa del escribano público, Juan Martinez de Ribafecha. Entre los hombres buenos que acudieron a la citada reunión encontramos los nombres de los tres que faltaron a la primera en casa del j̣udio Alfandaji ${ }^{10}$. Conocemos, pues,

Cerda Ruiz-Funes recuerda que en la ciudad de Murcia un privilegio concedido en 1267 hizo que el concejo pasase a denominarse "concejo de hombres buenos" y en otro texto se cita a los "omnes buenos reunidos concejeramente». Op. cit., pág. 173

${ }^{8}$ Cerda Ruiz-Funes, "...asimismo el Fuero de Guadalajara hace sinónimos "bono omnes' y hombres honrados..". Op. cit., pág. 170.

${ }^{9}$ Asi, Merchan Fernandez, Carlos, en Gobierno Municipal y Administración Local en la España del Antiguo Régimen. Madrid 1988, pág. 54, dice: "El regimiento en sus origenes era una asamblea representativa integrada por un número determinado de hombres buenos".

${ }^{10}$ Ordenanzas de 1346. Real Biblioteca de El Escorial. Códice X-1I-19.: «Los doze omes buenos que han de ver fazienda del concejo de este dicho logar». De las reuniones efectuadas los dias 1 y 22 de diciembre de 1346, obtenemos sus nombres.

- Garci Pérez Gallego

- Alvar Pérez

- Diego Fernández

- Alonso Pérez Pecha

- Alvar Ruiz

- Ruy Pérez

- Estevan Fernández

- Diego Fernández

- Diego Pérez Recuero.

- Rodrigo Arias

- Alvar Sánchez

- Alvar Páez 
quiénes eran los hombres buenos de la villa de Guadalajara en 1346, aunque no su extracción social. Debian ser, desde luego, vecinos, con casa poblada en la villa y una probidad reconocida, pero desconocemos si todos eran caballeros. Lo temprano de la fecha nos induce a pensar que bien pudiera haber entre ellos tanto caballeros como pecheros ${ }^{11}$.

Según se lee en el preámbulo de las ordenanzas los hombres buenos de Guadalajara tenian la facultad de "ver fazienda del conçejo». Pero su participación en la redacción de esas mismas ordenanzas revela que además ejercian cierta potestad reglamentaria, aunque estuviera sometida en última instancia a la aprobación de la reina, señora de la vilia en aquella fecha. (Sujeción a una autoridad superior que, por otra parte, ha subsistido durante siglos). Así, los hombres buenos, aunque no se llamaran regidores, ni tuvieran todas sus prerrogativas, son también en Guadalajarara el antecedente del regimiento ${ }^{12}$.

\section{LA INSTAURACIÓN DEL REGIMIENTO EN 1405}

La instauración del regimiento en la villa de Guadalajara se cumplió de forma singular. Abundan las noticias acerca de la resistencia que muchas ciudades opusieron al sistema de regimiento ${ }^{13}$, pero en Guadalajara, en contraste, el regimiento llegó por iniciativa del común.

"Gonzalez Alonso, Benjamin, Sobre el Estado y la Administración en Castilla en el Antiguo Régimen. Madrid 1981, pág. 60: “Fueros tan importantes comos los de Soria y Cuenca, entre otros, exigirán para optar al ejercicio de dichos cargos concejiles, además de ser vecinos, se esté en posesión de caballo y armas, lo cual, es evidente, no se encontraba al alcance de la mayoria».

12 Montalvo Antón, Josè M.", "La participación politica de los pecheros en los municipios castellanos de la Baja Edad Media. Aspectos organizativos». en Studia Histórica, Historia Medieval N. ${ }^{\circ}$ VII. Salamanca, 1989, pág. 39: “...se establecia que el gobierno municipal quedaba en manos de una minoria de "hombres buenos que han de ver e ordenar los fechos e fazienda del concejo", esto es, los regidores, llamados ya de este modo pocas décadas después, los cuales, junto con la justicia, formaban el Ayumtamiento o Regimiento...".

${ }^{13}$ Destacamos entre otros el ejemplo que aporta para la ciudad de Murcia, Cerda RuizFUNES en su $O p$. cit., pág. 182; “En cambio, en Murcia, se adelanta en unos años con la creación de un concejo de cuarenta caballeros y hombres buenos, ya que lo establece Alfonso XI el 17 de diciembre de 1325. Parece que trataba de aplicar lo acordado en las Cortes de Valladolid del mismo año, donde se pedia la creación en las ciudades de un ayuntamiento de cuarenta miembros. El monarca justifica su disposición en el hecho de que la asamblea de muchas gentes, era causa de que se alborotasen las ciudades y que por ello no se cumpliera el servicio del rey ni el bien de la comunidad. Este concejo cerrado no fue del agrado de la ciudad, pues iba contra lo establecido en sus privilegios y surgieron disturbios y protestas que llegaron hasta el propio Adelantado Mayor, quien determinó expulsar de la ciudad a dos destacados vecinos y condenó a prisión a otros. Este hecho dió lugar a la creación en la ciudad de unas banderias o partidos" 
En 1405 el común presentó a los caballeros y escuderos de Guadalajara un cuaderno de condiciones para el buen gobierno de la misma, que incluia la propuesta de que se nombraran regidores "para que desagravien los agravios que fueron fechos por los alcaldes e ofiçiales». Del hecho no conservamos las actas originales, pero si un traslado de ellas, de 1417, del que nos hemos ocupado en otra ocasión ${ }^{14}$.

El cuaderno de 1405 proponia el nombramiento de ocho regidores. Es posible afirmar que esos ocho regidores constituyeron el primer regimiento de Guadalajara: El cuaderno no menciona en ningún momento la existencia anterior de otro cabildo de regidores; el escribano que en 1417 hizo la copia citada anotó en el margen superior este título: «Hordenanças de la villa del tienpo que no habia rregidores en ella".

No sabemos qué fuerza ejerció el común, pero logró la aceptación jurada de sus condiciones por parte de al menos 53 integrantes del estado de los caballeros y escuderos del término, que representan, sin duda, una proporción condiderable del mismo. Unos meses antes habia muerto el Almirante Diego Hurtado de Mendoza, señor de hecho, aunque no de derecho de la ciudad, y es probable que la relación de poder entre caballeros y común se hubiera equilibrado por ello.

En el origen del regimiento en Guadalajara late un enfrentamiento por el control de los oficios municipales. Citaremos cuatro hechos que prueban esta afirmación.

Primero, el Padre Pecha ${ }^{15}$, historiador de Guadalajara del siglo XVII, informa de que en el último tercio del siglo xiv los oficios municipales de

${ }^{14}$ LOPEZ VIllalba, José Miguel; "El Cuaderno de Condiciones del Comủn de la villa de Guadalajara de 1405", en Espacio, Tiempo y Forma, Serie III. Historia Medieval. Madrid, UNED, 1990, pág. 121-156.

${ }^{15}$ De todas las historias clásicas de Guadalajara. la más antigua conservada es la Historia de Guadalaxara de Fray Hernando Pecha que se remonta a 1632, aunque nosotros hemos utilizado la transcripción de Antonio Herrera Casado publicada por la Institución Provincial "Marqués de Santillana". Guadalajara 1977. En la página 190, afirma, el Padre Pecha. refirièndose al Almirante Diego Hurtado de Mendoza: «... finalmente tenia tan ganados a todos los de Guadalaxara. que no se meneavan en cosa grande ni pequeña, que no fuese con su pareçer, y llegó esta subjección a tanto, que teniendo los de Guadalaxara costumbre inmemorial de sortear los officios de aquella República y nombrar justiçias y regimiento. pusieron voluntariamente este derecho de elegir en manos del Almirante Don Diego para que él solo por su pareçer elegisiese los Ministros de la Justiçia cada año, de manera que desde el Almirante Don Diego entró en la casa del infantado el nombrar los señores della en Guadalaxara, alcaldes ordinarios, alguazil mayor y menores, juez de appelaçiones, Alcalde de Alcadas, Alcalde de Hijosdalgo, escrivano de Padrones. Alcayde de la fortaleza con todos los demás offiçios altos y bajos como si fuera señor absoluto de Guadalaxara, y se conservó este derecho de elegir en los señores de la Casa de Mendoza desde nuestro Almirante Don Diego por espaçio de çiento çinquenta años...". 
Guadalajara no eran nombrados por el Concejo, sino por el Almirante Diego Hurtado de Mendoza - aunque éste, puesto que la villa era de realengo, no tuviera títulos suficientes para ello- y explican que esta cesión por parte del Concejo al Almirante fue voluntaria y que con ella se quiso poner fin a las disputas que se producian siempre con ocasión de la elección de oficiales del Concejo.

Segundo, en 1401, Enrique III, ante las constantes quejas por la mala administración de la villa, aprovechó una ausencia del Almirante don Diego, en campaña contra los almorávides, para enviar un corregidor a Guadalajara, micer Ventura Venzón, que, aunque temporalmente, arrebató a Don Diego el control de los oficios de la ciudad ${ }^{16}$.

Tercero, en el mismo cuaderno de 1405, el común declara expresamente que su objetivo es que "todos seamos concordados e amigos conjuntamente con vosotros en rrazón de los ofiçios".

Finalmente, de los ocho individuos que componian el regimiento de Guadalajara ${ }^{17}$, seis eran nombrados entre los caballeros y escuderos y los otros dos entre los hombres buenos pecheros. Pero esta desigualdad no se mantenía en todos los casos: precisamente a la hora del juramento de los oficiales municipales, el común impuso como condición que éste se hiciera ante un ayuntamiento de carácter paritario, formado por los ocho regidores más los "quatros", representantes de las collaciones de la villa, es decir, formado por seis caballeros y seis representantes del común.

${ }^{16}$ Subre esta cuestión nos dice Layna SerRano en su susodicha Op. cit., t. I, pág. 118: «Al ausentarse de Guadalajara don Diego Hurtado para emprender su expedición marítima contra los piratas berberiscos el año 1400 , bien porque en la villa los amigos del Almirante mangonearan más de la cuenta, originándose disturbios, bien porque el monarca quisiera disponer por si de las alcaldias y demás oficios concejiles por ser Guadalajara propiedad realenga, el hecho es que nombró corregidor de la villa a su maestresala miçer ventura Venzón con facultad para usar de los cargos delegándolos en las personas que tuviera a bien, pues Enrique III por motivos que hoy se ignoran habia suspendido en sus funciones del regimiento de Guadalajara, al Almirante, concejo, caballeros, escuderos, oficiales y hombres buenos de la villa; lo cual, hace sospechar algún desbarajuste administrativo o algún atropello de los derechos reales en cuestión tributaria que obligara a aquella suspensión y al nombramiento de un corregidor o juez de residencia".

"Cfr. Mignot, Caroline, en su comunicación «EI patriciado urbano de Guadalajara (14541502)", en Actas del I Congreso de Historia de Castilla-La Mancha, Toledo (1988), t. VI, págs. 233-237 y MONSAlvo ANTON, Op. cit., pág. 48 


\section{CONFIRMACIÓN DEL PODER DE LOS REGIDORES}

Después de 1405, las primeras ordenanzas que vuelven a regular el regimiento están fechadas en $1417^{18}$. Apenas habian pasado diez años, pero en ellas está completamente asentada la figura del regidor.

En 1417, Juan II envió un corregidor a Guadalajara, lohan de Sant Andres, como "Justicia" de Guadalajara y su tierra. Este corregidor, y su alcalde, lohan Rodríguez de Vélez, se reunieron el 5 de septiembre de 1417 en la Cámara del Concejo con algunos regidores, jurados, caballeros, escuderos, representantes del común y otros vecinos ${ }^{19}$. Alli se de-

${ }^{18}$ En otros trabajos ( $E$ El cuaderno de Condiciones del ... de $1405 \%$, en Espacio, Tiempo y Forma, (1990); págs. 121-156, y “El ascenso de los caballeros y escuderos de Guadalajara y los privilegios reales. Siglos Xil-xv", en Actas del " Encuentro de Historiadores del Valle del Henares. Alcalá de Henares, Ayuntamiento, 1990, págs. 187-196) habiamos fechado estas ordenanzas en 1427, no en 1417, pues era la única fecha legible que recogía el Libro Registro de Escrituras, Privilegios y Ordenanzas de 1545, por aquel entonces nuestra única fuente. Esa decisión tomaron también los otros historiadores que han tratado estas ordenanzas.

Posteriormente la limpieza y restauración del citado Libro Registro a lo largo del verano de 1990, y el acceso a una segunda fuente -un traslado del siglo xv de dichas ordenanzas, que también se hallaba en restauración-- nos obliga a corregir la data inicial.

En el Libro Registro la fecha de las ordenanzas que nos ocupan está borrada y sólo nos informan de ella dos notas archivisticas que se contradicen: una indica 1427; otra, legible después de la restauración, 1417.

Pero el traslado del siglo $x v$ a que nos referimos se conservaba unido a otro traslado fechado en 1417, de las Ordenanzas o Condiciones de 1405, en letra similar y del mismo tipo de papel, como si a la hora de aprobar las nuevas se hubieran unido a una copia de las antiguas.

De modo que, por dos caminos, la nota de la fuente de 1544 y la semejanza del nuevo traslado con otro texto fechado en 1417, se llega a la conclusión de que las llamadas hasta ahora ordenanzas de 1427 lo son de 1417, y que la nota que indicaba 1427, tachada y sobreescrita, dudosa, fue un error de un lector apresurado que ha confundido a varias generaciones.

${ }^{19}$ Ordenanzas de 1417. Archivo Municipal de Guadalajara. 1H52.1 y Libro Registro de Escrituras, Privilegios y Ordenanzas: “... estando ende el bachiller lohan de Sant Andres corregidor e justicia en la dicha villa e su tierra por nuestro señor el rey, e lohan Rodriguez de Velez, alcalde en la dicha villa por el dicho corregidor e Lope Sánchez de Lasarte e Alfonso Carrillo e Diego Rodriguez de San Viçente e Juan Martinez de Fuentelenzina, regidores en la dicha villa e Ruy Lorenço, jurado e Sancho Fernández del Arco e Luis Gonçález de Toledo e Juan Ramirez de Arellano e Gonçalo Beltrán e Pero López de Lasarte e Alvar Rodriguez de Hita e Martin López de Santoyo e Nuño Fernández de la Fuente e Garci López de Trillo, fijo de Lorenço Ruiz e Ruy Ximenez Cherino e Martin Rodriguez Cherino e Fernán López de Buendia e Juan Alfonso, liçençiado, e Alfonso Gonçález de Sahagún. E otrosí estando ende presentes por parte del común e omes buenos pecheros de la villa, Garci Martinez de Fuentelenzina e Alvar García de Santistevan, sus procuradores del dicho común, e Pero Martinez, barbero, e Pero Martinez de Alhondiga e Gonçalo Garcia, espeçiero, e otros vezinos de la dicha villa y en presencia de mí, Pero Fernández, escrivano público en la dicha villa de Guadalfajara...". 
claró que habia frecuentes disputas entre los oficiales de las alcaldias, alguacilazgos y juraderías, tanto por la falta de corregidor que arbitrará entre ellos, como por la imprecisión de las antiguas ordenanzas, que no dejaban claras las competencias de cada oficio, los derechos que podian llevar sobre los asuntos que tratasen o el salario que debian cobrar. Se decidió, pues, arreglar las antiguas ordenanzas.

Pero ante todo, lo que se quiso asegurar fue el buen uso de su oficio por los regidores. Para ello, en la primera ordenanza regularon su jurisdicción. Los regidores no debian entrometerse en las cuestiones referentes a los oficios de alcaldes, jurados y alguaciles, salvo cuandos éstos actuasen injustamente, abusando de las preeminencias de su cargo, llevando salarios y derechos por encima de lo razonable, o nombrando fieles, andadores o tutores, basándose en las dádivas más que en las excelencias que mostrasen para el cargo, o prolongando los pleitos sin razón alguna, entre otros casos. Asimismo los regidores debian intervenir en los agravios que realizasen los caballeros de los montes o sus peones.

La ordenanza segunda disponia que el regimiento se reuniera en ayuntamiento cerrado al menos tres dias por semana: lunes, miércoles y viernes. Con ello se pretendía que todos los asuntos fueran resueltos con rapidez.

Con idéntica eficiencia proponía la ordenanza tercera, que se enmendaran los agravios realizados por los oficiales concejiles. Habia un plazo de tres dias, a contar después de que los regidores hubiesen dictado sentencia contra ellos. La ordenanza decimosegunda incide en esta cuestión del control de los oficiales por medio de los regidores, determinando las penas que se les imponian en el supuesto de no cumplir la sentencia.

Dado que eran los regidores los que debian dictar sentencia, la cuarta ordenanza exigia que no tomasen partido durante los pleitos, no favoreciendo ni a los acusados ni a los que se hubiesen querellado contra ellos. Si los regidores de Guadalajara tomaban parte en una reyerta de cualquier tipo, perdian el salario de un año, que se cifra, en la ordenanza sexta, en mil maravedis.

Los regidores libraban las cantidades procedentes de los propios del Concejo. Para que dicho libramiento fuese legal, debian acordarlo todos los regidores que en aquellos momentos se hallasen presentes en la villa, siempre que fuesen al menos cuatro y uno de ellos del común ${ }^{20}$.

Ordenanzas de 1417. AMGU. 1H52. 1 y Libro Registro de Escrituras, Privilegios y Or- 
Finalmente, cada 30 de septiembre, los regidores se reunian secretamente en la Iglesia de San Gil y echaban las suertes de las alcaldias, alguacilazgos, caballerías y yunterías.

Las ordenanzas de 1417 revelan que los regidores controlaban los aspectos más importantes de la vida municipal, pero que al tiempo ellos mismos estaban sometidos a ciertos controles: delimitación de competencias, régimen de sesiones o exigencia de imparcialidad. Por otra parte la composición mixta del regimiento, caballeros y común, se confirma en esta fecha: perviven los dos regidores del común y aún se exige que a la hora de acordar los gastos esté presente al menos uno de ellos, condición que no especificaba el cuaderno de 1405.

\section{EL SIGLO XVI: EL CORREGIMIENTO}

Los corregidores se convirtieron a lo largo de la Baja Edad Media en: «el factotum auténtico del gobierno municipal en todas las ciudades y villas castellanas donde existiese", según acertada definición de Carlos Merchán ${ }^{21}$. Su aparición, como sucesores de los llamados «juizes de salario" ${ }^{22}$ y de los alcaldes veedores ${ }^{23}$, puede fecharse en las Cortes de

denanzas. En la Ordenanza VII nos dice: "Yten que los dichos rregidores que guardaran e administraran et adelantaran en quanto pudieren e supieren la rrenta de los propios del dicho conçejo e que non gastaran ny distribuyran saluo en aquello y para aquello que tuvieren liçençia del dicho señor rrey que de ellos tomar e gastar e para los menesteres del dicho lugar e otro si que cada e quando que ovieren de dar algunos mandamientos para tomar de los dichos propios algunas contias de maravedis que ante que el tal mandamiento o mandamientos sea dado ni librado que primeramente sea acordado e hordenado por todos os rregidores que a la sasón estodieren regidentes en la dicha villa por ante el escriuano de los fechos del dicho conçejo e ansi acordado quel dicho escriuano lo escriva ansi en el libro o rregistro del dicho conçejo e lo firme de su nombre en las espaldas del tal mandamiento en senal de acordado e rregistrado pero que el tal mandamiento que non pueda ser acordado ni dado a lo menos sin quatro rregidores $w$ los dos rregidores de parte de la dicha común a lo menos de uno de ellos e firmada de su nombre e si de otra guisa fuere el tal mandamiento que non pueda ser valedero e sea ninguno y el mayordomo del dicho concejo que non lo cunpla".

${ }^{2}$ Merchán Fernandez, Carlos, Op. cit., pág. 79

22 GonzAlez Alonso, Benjamin; nos dice en la página 37 de su clásica monografia: El corregidor castellano (1348-1808). Madrid 1970: "Los jueces de salario habian sido el primer instrumento de la política regia de intervención en las ciudades que cubrió su finalidad durante determinado periodo. Los corregidores nacieron a su amparo y a lo largo de varios años se conservó la dualidad entre ambos".

${ }^{23}$ Bermudez Aznar, A., El corregidor en Castilla durante la Baja Edad Media (1348-1474) Murcia 1974, pág. 35 
Alcalá de $1348^{24}$, cuando los procuradores denominan al delegado regio "Corregidor de los pleitos de la justicia».

Dada la naturaleza extraordinaria del corregidor en aquellos primeros momentos no aparecieron ni multitudinariamente ni con carácter permanente. Por ello y a pesar de la posterior difusión que tuvieron en tiempos de Enrique $11{ }^{25}$ y de su sucesor Juan II, todavia en tiempos de Enrique IV, eran funcionarios poco habituales en los concejos castellanos. Habrá que esperar a las Cortes de Toledo de $1480{ }^{26}$ para que se dicten normas sobre estos oficiales para que dejen de ser algo excepcional en la vida municipal. Dichas normas, que habian tenido un precedente en las Ordenanzas otorgadas por Juan II en 1436, en Guadalajara ${ }^{27}$, desembocaron el 9 de julio de 1500, en los Ilamados «Capítulos para Corregidores y Jueces de Residencia» ${ }^{28}$. A partir de aquel momento el corregidor recorrerá un camino ascendente hacia una mayor asunción de competencias, alejándose cada vez más del papel de comisario excepcional con que habia llegado hasta los finales del siglo $x \vee$ y tranformándose ya con los primeros austrias en poderosos delegados del gobierno central.

En Guadalajara, la figura del corregidor no apareció de modo permanente hasta mediado el siglo xvı. Sin embargo, hay precedentes desde principios del siglo XIV, que exponemos cronológicamente a continuación.

La primera noticia de un delegado regio enviado a Guadalajara se remonta al 23 de mayo de 1341. Ese año, en un contexto histórico en el que se hicieron frecuentes los alcaldes veedores y enmendadores, fueron enviados por la reina a la villa de Guadalajara, Diego Juan de Santo Tomé y Juan Martínez Jurado, para "corregir los fechos de la tierra" y, entre

${ }^{24}$ González Alonso, B, En su obra El corregidor castellano... nos puntualiza: «La alusión de las Cortes de Alcalá de 1348 a los corregidores de "pleitos de la justicia", pág. 35.

25 Mitre Fernandez, Emilio, La extensión del régimen de corregidores en el reinado de Enrique III de Castilla. Valladolid 1969. Universidad de Valladolid. En dicho trabajo hace una exhaustiva relación de los primeros corregidores: Murcia 1399; Sevilla, 1396; Córdoba 1402; Jaèn 1396, Guipúzcoa 1394 y Vizcaya tambien en 1394, entre otros.

2 GonzÁlez Alonso en la página 77 de su obra El corregidor castellano...; reproduce un significativo fragmentc de la Crónica de los Reyes Católicos de Pulgar en el que leemos: «El Rey e la Reyna acordaron en aquel año de enviar corregidores a todas las ciudades e villas de todos sus reynos donde no los habian puesto".

${ }^{27}$ Dichas ordenanzas fueron redactadas en Guadalajara el 15 de diciembre de 1436, por hallarse Juan II en dicha villa, para asistir a la boda de don Diego Hurtado y doña Brianda de Luna, segun nos refiere Layna Serrano en su Op. cit.. t. I, págs. 195-198.

${ }^{28}$ Gonzalez Alonso, en su obra El corregidor...., tiene la opinión de que: "Los Capitulos de 1500 no son exhaustivos componen un nucleo estimable y representan un considerable avance si se les compara con la caracteristica dispersión y menor vigor de las normas anteriores», pág. 81. 
otras cosas, aprobar unas ordenanzas de oficios ${ }^{29}$. Las mismas que, como ya vimos, serian enmendadas en 1346, por los alcaldes de la reina, Tel Fernández de Toledo y Garci Alfonso Triguero de Toro, en los cuales hallamos nuevamente unos delegados reales.

Más adelante, en 1401, Enrique III, aprovechando la ausencia del Almirante Diego Hurtado de Mendoza, como dijimos, envió al fin un corregidor a Guadalajara, Miçer Ventura Vençón ${ }^{30}$, primero de los oficiales que con este nombre habrian de llegar. Apenas estuvo unos meses: ese mismo año el Rey devolvió los oficios de la villa al Almirante. En 1417, ya muerto el Almirante, llegó un nuevo corregidor, lohan de Sant Andrés, que acudió a Guadalajara con la misión expresa de "desatar y entender los agravios que los oficiales et alguazil et otras personas de esta dicha villa fazian y cometian contra justiçia” ${ }^{31}$.

El historiador local Alonso Núñez de Castro, que sigue ciertos Anales de Guadalajara, obra perdida de Francisco de Medina y Mendoza, cita a un tal Pedro de Guzmán como corregidor de Guadalajara en el año $1455^{32}$, y Azcona y Ulloa a su vez, aportan datos sobre la presencia de corregidores en la ciudad de Guadalajara en 1494 y 1515, respectivamente ${ }^{33}$.

El 7 de noviembre de 1528, a causa de ciertas desavenecias entre don Diego Hurtado de Mendoza, tercer duque del Infantado y algunos representantes de la ciudad ${ }^{34}$, Carlos I nombró juez de residencia, que vale

${ }^{29}$ Real Biblioteca de San Lorenzo de El Escorial. Códice X-H-19. : «En veinte e tres dias de mayo era de mill e trezientos e setenta e nueve años, vinieron a Guadalajara, Domingo Juan de Santo Tomé, vezino de Salamanca e Juan Martinez Jurado por corregir los fechos de la tierra con carta de la reyna e entre otras cosas fizieron hordenamiento....".

${ }_{30}$ Para Mitre, Emilio éste fue el más significativo de los fracasos de la politica regia de Enrique III, sobre la extensión del corregimiento. Op. cit., pág. 42.

${ }^{31}$ Ordenanzas de 1417. AMGU. Libro Registro de Escrituras, Privilegios y Ordenanzas. En el preámbulo de dichas Ordenanzas vemos que: "...luego el dicho conçejo, rregidores y omes buenos dixeron que por rrazón que en los tienpos pasados tanto que los ofiçiales de las alcaldias e juraderias e alguazilazgo de la dicha villa tovieron el dicho concejo y cavalleros y escuderos e omes buenos según que los ante tenian e tienen non aviendo corregidores en la dicha villa cmo despues aca que avia nasçido e rrecresçido entre ellos muchas disinsiones e discordias ansi por rrasón de algunas obscuridades que avia en el fuero e hordenanças de esta dicha villa ansi en rrasón como devian usar los rregidores sus oficios e...".

32 Núnez de Castro, Alonso, Historia eclesiastica y seglar de la muy noble y muy leal ciudad de Guadalaxara. Madrid 1653, pág. 106.

33 Azcona, T., Isabel la Católica. Estudio critico de su vida y reinado. Madrid 1964, B.A.C., pág. 343

UlıoA, M., La hacienda real de Castilla en tiempos del reinado de Felipe II. Roma 1963 pág. 37.

34 Laina Serrano, Op. cit., t. III, págs. 107-109. 
como corregidor, al licenciado Andrés Ramirez de Alarcón ${ }^{35}$. Una vez acabada su misión y ante su negativa a abandonar la ciudad el duque reclamó los derechos que le asistian en el nombramiento de justicias ${ }^{36}$. Ramirez de Alarcón abandonó la ciudad en junio ${ }^{37}$. Desde Toledo el Consejo de Castilla ordenó con fecha 11 y 12 de agosto de 1529 que tanto el juez de residencia Ramirez de Alarcón como su teniente el licenciado Alonso de Sensever entregaran las varas de la justicia a sus respectivos dueños ${ }^{39}$. El teniente Sensever asistió por última vez a las sesiones del Concejo el día 13 de agosto de ese mismo año ${ }^{39}$.

En 1543 un nuevo pleito enfrentó a la ciudad y al Duque del Infantado. La ciudad queria arrebatar al Duque el derecho a nombrar los oficios concejiles ${ }^{40}$ y que fuera el mismo rey, o su delegado, el que repartiera los cargos. Carlos 1 intentó una solución salomónica el 3 de noviembre de 1543: se comprometió con la ciudad a enviar corregidores y con el Duque a que fueran de su agrado ${ }^{41}$. Así, en 1543 llegó a Guadalajara Antonio de Quesada, primero de los corregidores que ya sin interrupción habrian de sucederse en la presidencia del ayuntamiento. Quesada, merced a las prorrogas habituales de la época permaneció en el cargo hasta el 28 de junio de $1545^{42}$. Ese mismo dia le sucedió el licenciado Alonso Pérez de Arteaga, al cual reemplazó el licenciado Pedro de Arceo, en 1546.

\section{EL SIGLO XVI: EL NUEVO RÉGIMEN LOCAL}

La breve estancia del corregidor Arteaga no impidió que dicho delegado real y los representantes de la ciudad redactaran unas nuevas or-

35 AMGU. Libros de Actas de Sesiones. 1528-1531. Fol. 2 verso.

36 Layna Serrano, Op. cit., t. Ill, pág. 108.

3. Según consta en el AMGU. Libros de Actas de Sesiones. 1528-1531. Fol. 84, verso-85 recto; el juez de residencia Ramirez de Alarcón, habia salido de la ciudad con la excusa de un viaje el 29 de Junio de 1529.

${ }^{38}$ A.H.N. Casa de Osuna. Legajo 3001. Recogido por Layna en su Op. cit., t. III, pág. 109.

39 AMGU. Libros de Actas de Sesiones. 1528-1531. Fol. 98 verso.

${ }^{40}$ Layna Serrano, en su Op. cit.. t. III, págs. 173-174, sigue al historiador Hernando Pecha el cual, refiriéndose a la entrega de los citados oficios al Almirante Diego Hurtado dice en la página 93 de su Op. cit.: “... esto suçedió el año de mill y treçientos y noventa y çinco años, siendo el Almirante de veinte años de edad".

${ }^{41}$ De estos nombramientos delegados podemos ver un lejano precedente en el año 1399 cuando Ruy López Davalos, Duque de Arjona, viaja a Murcia con plenos poderes para poner y quitar corregidores. Mitre Fernandez, E. Op. cit., págs. 25-26.

4? Gonzalez Alonso, "La anualidad va siendo insensiblemente suplantada por la bianualidad, aunque los nombramientos siguen despachandose con arreglo a la más estricta anualidad anterior", El corregidor castellano..., pág. 156 
denanzas de gobierno, en parte en la sesión de concejo de 7 de Octubre de 1545 , aprobadas por real provisión al año siguiente ${ }^{43}$.

Las ordenanzas de 1546 detallan la posición de los regidores en la cámara del Ayuntamiento. El primer puesto correspondia al del corregidor, como representante del poder real en el municipio; la distribución de los regidores se fundaba en la antigüedad en el cargo, y señalaba el orden en las votaciones ${ }^{44}$.

Los regidores de la ciudad de Guadalajara estaban obligados a informar al rey, alli donde éste se encontrase, de todos los problemas graves que pudiesen surgir en la vida municipal. Asimismo debian acompañar al corregidor cuando éste saliese a visitar el término y las mojoneras, por turno, sin que pudieran volver a salir, hasta que todos los regidores de la villa hubiesen cumplido con esta obiigación.

Son de especial interés las atribuciones de los regidores en materia urbanistica, que revelan la capacidad del regimiento para controlar el desarrollo urbano: No se podian construir edificios nuevos sin acuerdo positivo y les correspondia el libramiento de las cantidades necesarias para las obras públicas.

Pero si bien es cierto que los regidores poseían una amplia serie de prerrogativas - desde poder rebajar las penas a los condenados por cortar leña en el monte, a librar dinero de los propios-, no lo es menos que siempre tuvieron algún escollo que salvar, bien fuese el del representante real o el de los representantes de la ciudad. Así, podian rebajar las penas del condenado, pero debian hacerlo ante el juez; tambien podian librar dinero de los propios, pero debían hacerlo en presencia del Justicia, dentro del Ayuntamiento y ante un escribano público (ya no ante un representante del común).

Para que la ciudad de Guadalajara no olvidase las ordenanzas de 1546, se acordó que se leyeran en público el dia 2 de enero de cada año. Entendemos que no solo éstas, sino todas las que estuvieran vigentes.

\section{CONCLUSIONES}

Hemos procurado, en una primera aproximación, establecer, aun como hipótesis, un ritmo, una cronología.

\footnotetext{
${ }^{43}$ A.M.GU. $1 \mathrm{H1.30}$

${ }^{44}$ La transcripción completa de la reunión del Concejo de Guadalajara del dia 7 de octubre de 1545 va en apéndices.
} 
Asi, a la vista principalmente de las ordenanzas, pueden señalarse algunas fechas clave de la historia del gobierno municipal de Guadalajara, que en principio, aconsejan otros tantos períodos de estudio: 1) De 1085 a 1405: Del Concejo Abierto al Regimiento; 2) De 1405 a 1546: Instauración y evolución del Regimiento, y 3) Desde 1546: El Corregimiento, que culmina la pérdida de la autonomia municipal.

En comparación con otras villas, el regimiento de Guadalajara es tardío: unos cincuenta años posterior al de Zamora, Segovia, Burgos, León o Madrid. La razón de este retraso no se debe a la ausencia de conflictos, que en otras partes obligaron al rey a establecer por la fuerza el nuevo sistema de gobierno, sino muy probablemente al dominio que mantuvo sobre la villa el Aimirante don Diego Hurtado de Mendoza.

Por ello, cuando murió el Almirante, en 1404, los acontecimientos se precipitaron. Como en otras partes el regimiento se estableció para sustituir unas formas de gobierno poco adecuadas, pero a diferencia de otras poblaciones, según parece, la iniciativa no vino del rey sino del común.

Para el común, el regimiento no era por si mismo algo negativo. Se reconocía el predominio de los caballeros, pero, dada la composición de las asambleas, se aseguraba que la representación del común fuera escuchada en los asuntos de mayor importancia: el nombramiento de los oficios y el libramiento de los propios.

Del mismo modo, tampoco la iniciativa de la instauración permanente del corregimiento en Guadalajara partió del poder real, ni fue contra los deseos de la oligarquía urbana sino a favor de ella, para asegurar sus intereses frente a los Mendoza.

No olvidemos que cuando se aprobaron las ordenanzas de Guadalajara de 1546, hacia ya unos años que la politica austriaca sobre ventas de oficios habia suscitado protestas y llevado a las Cortes de Valladolid de 1523 , a reaccionar en contra de las mismas ${ }^{45}$. Las primeras noticias sobre ventas de oficios de regidores datan, según Margarita Cuartas, de $1543^{46}$. Por tanto las citadas ordenanzas de 1546 , se hallan en la frontera temporal entre la posesión de un oficio como merced y el acceso a su propiedad por la compra del mismo. Las normas que distribuyen a los

${ }^{45}$ Cuartas Rivero, Margarita, "La venta de oficios públicos en el siglo Xvl», en Actas del IV Symposium de Historia de la Administración. Madrid, I.N.A.P. 1983, págs. 225-261. Dicha autora nos dice en la página 228: "Hay un cambio decisivo en la política real sobre los oficios, pues de ser éstos simples objetos de una concesión real, gratuita, utilizada para premiar fidelidades y servicios, se pasa a considerarlos como una manera de obtener recursos, como otra renta de la Hacienda".

46 Cuartas Rivero, Margarita, Op. cit., pág. 230. 
regidores en torno al corregidor revelan que dicha oligarquía se hallaba ya consolidada, habiendo desterrado al común del gobierno, y deseaba refiejar con claridad la posición de cada uno en la jerarquia local.

En suma, en ambas ocasiones, establecimiento del regimiento y del corregimiento, se persiguió la racionalización del sistema de gobierno para evitar los abusos de un poder superior: primero, en defensa del común frente a los caballeros y escuderos; después, en defensa de los sucesores de aquellos caballeros y escuderos frente a la alta nobleza. 


\section{APÉNDICE DOCUMENTAL}

El documento $n .{ }^{\circ}$, es un acta de la sesión del concejo de Guadalajara del 7 de octubre de 1545 , en la cual se redactaron y aprobaron, por parte del corregidor y los regidores de la ciudad, unas ordenanzas referentes al gobierno municipal.

El n. II, es un acta de sesión del concejo de Guadalajara de fecha 27 de mayo de 1546 , en la cual se recoge el recibimiento efectuado al nuevo corregidor, el licenciado Pedro de Arceo.

a) Grafias

1. Se ha respetado la grafia de los documentos originales.

2. Los errores de repetición de palabras se han señalado mediante (SIC).

3. Las palabras situadas entre lineas han sido señaladas colocándolas entre $<>$.

4. Lo que consideramos que han sido dos olvidos del escribano los hemos añadido entre [ ].

b) Abreviaturas

1. Todas las palabras abreviadas se han desarrollado sin señalar las letras suplidas.

c) Uso de mayusculas

1. Se ha seguido la costumbre moderna para nombres de personas y topónimos.

\section{d) Puntuación}

1. Hemos seguido el sistema moderno de puntuación.

DOCUMENTO N. 1

1545, octubre, 7. Guadalajara. Ayuntamiento.

Acta de sesiones: Aprobación de nuevas ordenanzas.

AMGU: Libros de Actas (1544-47). Folio 56 recto a 58 recto.

En la çibdad de Guadalajara a siete dias del mes de otubre año del nasçimiento de Nuestro Salvador Ihesu Christo de mil e quinientos e quarenta e çinco años, estando juntos los muy magnificos señores justiçia e rregidores de la dicha çibdad en la casa de su ayuntamiento segund que lo han de uso e de costunbre de se ayuntar. Espeçialmente estando en el dicho ayuntamiento los señores: el licenciado Alonso Pérez de Arteaga, corregidor e juez de rresidençia en la dicha çibdad e su tierra por sus magestades, e Melchor de la Bastida y Gaspar de Guzmán e Gaspar Gutierrez de Porras e don Pero Gómez de Çibdad Real e don Melchor de Guevara, rregidores de la dicha çibdad, proveyeron lo siguiente, estando presentes Bernardino de Medina, jurado en la dicha cibdad e Lope de Xerez e Pero de Sacedón, quatros del común de la dicha çibdad.

El dicho señor corregidor e juez de rresidençia en presençia de los dichos señores regidores e ayuntamiento dixo que para la buena governaçión de la dicha çibdad y abtoridad del dicho ayuntamiento, convenia para quitar dubdas y desynsiones para adelante proveer en ciertas <cosas>. Con acuerdo del rregimiento proveyó las cossas siguientes.

Primeramente en los asientos de los señores rregidores: 

fuere.

El señor marqués por más antiguo a la mano derecha del señor corregidor que es o

El señor Melchor de la Bastida a la mano izquerda.

El señor Juan Gorbalán, baxo del señor marqués a la mano derecha.

El señor Gaspar de Guzmán, baxo del señor Bastida la mano izquerda.

El señor Gaspar Gutierrez, baxo del señor Gorvalán a la mano derecha.

El señor Francisco de Guzmán, baxo del señor Gaspar de Guzmán a la mano izquerda.

El señor don Pero Goméz, baxo del señor Gaspar Gutierrez a la mano izquerda.

El señor Diego de rreinoso, baxo del señor don Francisco de Guzmán a la mano izquerda.

El señor don Melchor de Guevara, baxo del señor don Pero Gómez a la mano derecha.

El señor Álvarez, baxo del señor rreynoso a la mano izquerda.

Esto no perjudicando el derecho de don Luys Zagal y de Antonio de Torres, rregidores que al presente no estan en el ayuntamiento, para que al tienpo que entren a rregir se vea en que tienpo fueron rreçebidos y que derecho tienen en los dichos asientos.

Otrosi, que en absençia del rregidor más antiguo se asyente en su lugar el segundo a la manera que le cabe y asi de esta manera bayan sienpre por su horden.

Otrosi, que en los botos quando alguna cossa se botare en el dicho ayuntamiento hablen y boten los dichos señores rregidores por su orden y antigüedad.

Otrosi, que sea guardado çerca de la horden que sea dada de las cossas en que han de entender los señores rregidores fieles lo que esta asentado y acordado en este libro por los señores del rregimiento a primero día del mes de julio de este año, a fojas treynta y çinco.

Otrosi, que en la vissita de la carçel al tienpo que en lo quel señor corregidor que 10 fuere la visitare, que en lo que toca a los señores rregidores que an de estar presentes que en este caso se guarden las leyes y porque sepan que se haze justiçia que esten en tal visita los señores regidores que quisieren o los cavalleros fieles

Otrosi, que al tienpo que el señor corregidor que es o fuere saliere de visita de los lugares de la juridiçión y a visitar los terminos y mojoneras que conforme a las leyes que estos reynos es obligado y que vaya con el un señor rregidor, el qual sea nombrado por los señores del rregimiento por el qual nombramiento sean llamados todos los señores rregidores que estoviern en la çibdad y que el que fuere una bez no vaya otra hasta que aya corrido por todos.

Otrosi, porque entre los señores rregidores ay algunas diferençias sobre en que lugar a de firmar cada uno de ellos, diziendo que una ordenança antigua que dispone que los rregidores que fueron nombrados al tiempo que en esta çibdad se hizieron perpetuos, ubo dos de ellos que avian de abian de (SIC) ser presentes en los ayuntamientos de esta çibdad para acordar y formar las libranças y que sin ellos no se pudiese hazer en el rregimiento de los quales susçedieron los señores Melchor de la Bastida y Gaspar de Guzmán, rregidores <por> la qual hordenança estavan en costunbre de firmar los postreros. La qual hordenança ha mucho tienpo que quebró y no se usa ningunda. Que de aqui adelante los señores rregidores que al presente son de la dicha çibdad y los que fueren adelante firmen las libranças que se fizieren y los otros abtos y acuerdos que como rregidores ovieren de firmar cada uno de ellos segund su antigüedad, sin guardar la horden que fasta aqui se a tenido cerca de esto. En lo tocante a estas firmas contradixo el dicho señor don Melchor hasta tanto que se comunique con los otros señores rregidores absentes. 
Otrosi, por que se halla que (SIC) de la pesquisa secreta y por otras cossas que hasta aqui se an hecho algunos edefiçios en esta çibdad syn acuerdo de los señores del rregimiento que de aqui adelante no se hagan los tales edefiçios syn acuerdo del dicho rregimiento y con preçeder ynformaçión de utilidad del dicho edefiçio e de la nesçesydad que ay del e que esta ynformaçión se haga a pedimiento del procurador de la dicha çibdad e de qualquiera de los señores rregidores y sy de otra manera se hiziere algund edefiçio, que el procurador de la dicha çibdad to contradiga e rreclame, so pena de pribaçión del ofiçio.

Otrosi, que las penas pertenesçientes a la dicha çibdad asy de montes como de otras que por leyes o ordenanças de la dicha çibdad le pertenesçieren no se puedan conmutar por el señor coregidor ques o fuere sin lo consultar con el dicho rregimiento so pena que sea visto querer hazer gracia dello de su bolsa. Esto no se entiende a de [hazer] en el su corregimiento e el dicho ayuntamiento [como] fasta agora tienen proveydo.

Otrosi, que las condepnaçiones que los tales juezes hizieren para cobrar penas de la dicha çibdad no las puedan gastar por su propia abtoridad syn lo consultar con el dicho rregimiento e que si de otra manera lo hiziere sea visto quererlo gastar de su bolsa e en lo del señor corregidor presente no se entienda procede liçençia del rregimiento. Lo qual todos acordaron que se guarde y cunpla so pena de veynte mil maravedis para los propios de la dicha çibdad

Licenciado Alonso Pérez Gaspar Gutiérbez de Porras

Pero Gomez

(Rúbrica)

DOCUMENTO N:2

1546, mayo, 27. Guadalajara. Ayuntamiento.

Acta de sesiones: recibimiento del corregidor Pedro de Arceo.

AMGU: Libros de Actas.1544-1547. Foi. 95 recto.

En la çibdad de Guadalajara veinte e siete dias del mes de mayo, año del nasçimiento de Nuestro Salvador Ihesu Christo de mil e quinientos e quarenta e seys años e estando en el ayuntamiento de la dicha cibdad los muy magnificos señores corregidor e rregidores de la dicha çibdad para rresçebir al señor liçenciado Pedro de Arzeo, para corregidor de la dicha çibdad, espeçialmente estando en el dicho ayuntamiento los señores: liçenciado Alonso Pérez de Arteaga, corregidor e Juez de rresidençia en la dicha çibdad e su tierra por sus magestades, e Juan Gorvalán e Gaspar de Guzman e Gaspar Gutierrez de Porras e don Melchor de Guevara e Pero Ruiz de Alarcón, rregidores y estando presentes Manuel Melendez e Pero de Pastrana, jurados e Francisco de Ribera e Lope de Perea, quatros del común de la dicha çibdad, en presençia de mi Juan de Santa Maria, escribano, e testigos de yuso escriptos, paresçio presente el muy magnifico señor liçenciado Pedro de Arzeo e presentó la provisión de su corregimiento del thenor syguiente.

$$
\text { aqui }
$$

E presentada, el dicho señor corregidor la tomo en su mano e obedesçió e puso sobre su cabeça, e en quanto al cunplimento, rresçibió juramento en forma del dicho liçenciado Pedro de Arzeo segund forma de derecho, valiendo jurado le entregó las varas de la justiçia. 
Concejo abierto, regimiento y corregimiento en Guadalajara (1346-1546)

E luego el dicho señor liçenciado Arzeo corregidor nombró por alguasil a Juan de Peralta el qual juró en forma.

Liçenciado ARzEo

(Rúbrica) 